\title{
Nuevos datos documentales sobre Enrique Egas y la Catedral de Coria
}

\author{
María del Carmen Sanabria Sierra*
}

\section{RESUMEN}

La revisión de las Actas

Capitulares de la Catedral de Coria (Cáceres) ha puesto de manifiesto la intervención

del maestro Enrique Egas. Hacia agosto de 1495 el cabildo mantiene los primeros contactos con el maestro Enrique y le encarga la construcción de los pilares de su presbiterio.

En la remodelación de la lglesia existente se plantea la consecución de una planta de salón que actualmente con la nueva iluminación ha alcanzado unas dimensiones majestuosas, muestra su perfección y preludia las plantas de Toledo y Granada.

Posiblemente este logro arquitectónico es la adecuación al marco preexistente, la mezquita musulmana que en los tres casos existió.

\section{ABSTRACT}

The review of the Chapter Acts of Coria's Cathedral (Caceres) has shown the intervention of Master Henry Egas. At August 1945, the Chapter initiated the contacts with Master Henry and asked him to build the pillars of the presbytery. When the church was remodelled, the room plan got majestic dimensions with the new lighting, announcing the ones of the cathedrals of Toledo and Granada. This architectonic achievement is possibly the adaptation to the existing framework: the Muslim mosque which had been in existence in the three cases.

* Profesora-tutora del Centro Regional de Plasencia. 
La revisión de las Actas Capitulares de la Catedral de Coria (Cáceres) ha puesto de manifiesto la intervención del maestro Enrique Egas en la construcción de los pilares de su presbiterio. La importancia de este descubrimiento radica en que su relación con esta Catedral, la establece el profesor Mogollón en fechas más tardías ${ }^{1}$ y sólo como asesor del cabildo.

También se ha podido constatar el trabajo de Copín de Holanda documentado en las Actas Capitulares trabajadas. Hasta ahora sólo se conocía su presencia en el codicilio testamentario al que se refiere el profesor $\mathrm{F}$. J. García Mogollón ${ }^{2}$, los trabajos de Carmen Sánchez-Juan Carlos Rubio ${ }^{3}$ y otros autores. Aprovechamos esta ocasión para dar a conocer otros datos relevantes que aparecen en estas Actas entre los años 1480 a 1497.

En la década de los ochenta del siglo xv, el Cabildo de la catedral de Coria decide acometer una de las restauraciones de la iglesia. Así se emprenderán una serie de obras de desigual importancia. Unas - las más importantes- afectarán directamente a su estructura o se encaminarán a la ejecución de capillas; las otras tendrán relación con la reparación de los órganos, con la construcción de un salterio o con la confección de prendas de vestir como capas, casullas, etc. A tal fin le será encomendada a distintos canónigos e incluso a un sastre la tarea de ir de feria en feria, especialmente a la de Medina del Campo para efectuar las compras pertinentes de ornamentos, brocados y sedas.

Cronológicamente el primer caso en que nos detendremos es el referido al levantamiento de una capilla que según las Actas Capitulares, se aprueba su realización el viernes 31 de mayo de 1481. La responsabilidad de la obra le es otorgada a un maestro de nombre Fabián ${ }^{4}$ del que actualmente carecemos de datos. Algunos canónigos insisten en llevar adelante la construcción ante la oposición de otros que consideran excesivos los problemas económicos presentados por el contador. Incluso el arcediano porfía con el chantre que tenían que realizarla e incluso "ansy mysmo amenaço e diso Rodrigo Álvarez arçediano de cuentas, disiendo muchas cosas que avian de faser e aconçertar " 5 .

El 4 de enero de 1494 encontramos que Alonso de Jahen, en ese momento canónigo mayordomo y encargado de las cosas de la fábrica de la

Florencio-Javier GARCia Mogolıón. La Catedral de Coria. León. Edilesa. 1999. Págs. 56, 57, 61. Garcia Mogollon. (1999). Pág. 79.

Carmen Sanchez y Juan Carlos Rubio. Coria. León. Everest. 1983. Pág. 102.

4 ARCHIVO CATEDRAL DE CORIA (ACC), ACTAS CAPITULARES (AC), Legajo (Leg.) 170 , Documento (Doc.). 2, Hoja $(H) 25$ vuelto (vto).

5 ACC, AC, Leg. 170. Caja 1. Doc. 2. H. 26. 
iglesia, libra dos mil maravedis a Tomás entallador para pagarle los cajones que ha realizado ${ }^{6}$. El 12 de febrero de 1494 vuelven a mandar a Jahen que «de a Estevan Gonzalez e Tomas ${ }^{7}$ entalladores, a cada uno 20 reales de lo de la fábrica, que es a su cargo, para la obra de los caxones que hasen para la dicha iglesia. Ende gelos con este libramiento e con sus cartas de pago le serán recibidos ante él, los dichos cuarenta reales ${ }^{8}$.

El 19 de junio de 1495 leemos un encabezamiento de párrafo que indica «libramiento para Thomas entallador», en su momento, los señores del Cabildo mandan "a Cabeçalino, canónigo mayordomo de la dicha yglesia, que de quinientos maravedis a Thomas entallador, los quales le de de los de la iglesia e los quales se le mandaron dar para socorro e sus neçesidades, con tanto que se vean las cuentas de lo que se le a dado y pague el dicho Tomas lo que le fuese alcançado e resalido de mas de su salario. Cartas" ${ }^{\text {. }}$.

Unos meses más adelante encontramos a Copín de Holanda realizando la sepultura del obispo don Pedro Ximénez de Préxamo; en concreto el día 30 de octubre de 1495 se recoge: "mandaron a Cabeçalino que de la iglesia de un castellano a maestro Copin por que vino a mostrar la muestra de la obra que se ha do faser en la iglesia, e dando gelo con este le será recibido en cuenta» ${ }^{10}$. Por tanto, a partir de esta fecha comenzarían las obras del sepulcro del obispo don Pedro Ximénez de Préxamo.

El Cabildo autoriza la ubicación del sepulcro en su actual emplazamierito el miércoles 29 de diciembre de 1495 en la reunión mantenida manifiestando: «... y myrando a su persona ...y al bien que ha fecho a la dicha iglesia e fará de aquí adelante...por lo suso dichas cabsas y por otras muchas virtudes y noblezas que en él concurren...le señalavan e nombrarían y davan logar en la dicha iglesia para que pueda haser e definar su sepultura dentro en la dicha iglesia, entre las capillas del altar mayor y de Sant Miguel, fasia la mano derecha de cómo el saçido mas se vuelve al altar fasia el pueblo.... libremente syn obstáculo ni otra condición alguna e gelo davan, e dieron y donavan, donaron e cartas otorgaron fuerte contrabto e cartas, testigos Miguel Feas, Alonso Montero notarios e Juan de Medaño y Diego Gallos pertiguero de la dicha yglesia» ${ }^{11}$.

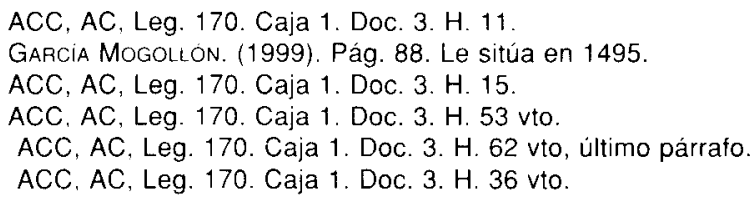


Después de su muerte, el $\mathbf{1 3}$ de agosto de 1495 se recoge que el "obispo mando en su testamento faser çiertas obras en la dicha iglesia e ninguna dellas esta començada e para faser las dichas obras mando en su testamento que se pagasen de sus asientos e bienes todos los maravedis que en ellas montare, por ende dieron que sy en algund tiempo el nuestro my santo padre o los reys nuestros señores o otra quales quier persona les demandaren los dichos marcos de plata, quellos han resçebido para la dicha yerva, la qual han de ser enega a la mesa capitular o lo quales han dado o dieren y pagaren padar y pagar a los maestros que fisieren las dichas obras de la dicha iglesia, que su señoria mandó faser o les molestaren e enquetaren a los dichos testamentarios y acudan uno dellos sobrelo suso dicho que ellos desde aquí se obligavan e obligaron..." ${ }^{12}$. Algo más adelante, después de las fórmulas obligadas, en el tercer párrafo se dice: "disponer e contratar e ordenar con maestre Copin sobre los arcos e mármoles de la dicha iglesia e para todo ello les encargaron las conçiencias e cartas» ${ }^{13}$.

Por lo que cuentan las Actas Capitulares parece derivarse que no se han comenzado las obras, pero el Cabildo, en este agosto de 1495, no deja de buscar a los artífices que las Ileven a cabo. En el plano de la arquitectura sobresale la diputación que realizan sobre el "chantre, el maestrescuela y Juan Lópes del Barco, canónigo, el licenciado Castillo, para que hablen con maestro Enriques sobre los pilares de la dicha iglesia $e$ dalle a faser la dicha obra» ${ }^{14}$.

Por tanto, en el verano de 1495 se tienen los primeros contactos con Enrique Egas y en el invierno comenzarian las obras de la iglesia y el sepulcro se adosa al lateral derecho del presbiterio.

Los pilares y la nave que configuran el mismo serian obra de Egas, de ahí que años más tarde cuando la Catedral comience a tener problemas en su cimentación se le volverá a llamar, como señala Mogollón ${ }^{15}$, «hacia 1529 o 1530 quizá visitó las obras el famoso arquitecto Enrique Egas, que actuaba en la catedral de Toledo" ${ }^{16}$, para que de su veredicto. Él conocía como se había levantado esa zona de la fábrica y por tanto era una de las personas indicadas para abordar la solución.

Durante estos años encontramos a los dos grandes maestros trabajando en Toledo, por lo que podemos ver la relación de los planteamientos

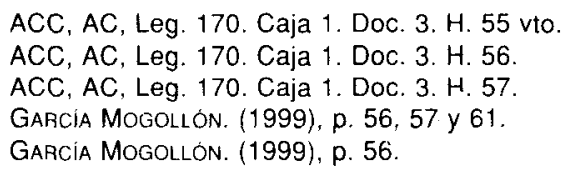


que se hacen en esta obra con la fábrica de Toledo. Evidentemente, por la fecha en la que nos movemos en el Acta Capitular, debió ser en Coria dónde el maestro experimente la nueva tendencia de la planta de salón. En análisis posteriores y utilizando otra documentación se podrá determinar si sus dimensiones están condicionadas por falta de numerario o porque la capacidad desarrollada era la suficiente para albergar su comunidad. Pero sí parece verosímil que a partir de esta experiencia Enrique Egas mejorara los planos de la Catedral de Toledo y de Granada.

No obstante, los diversos avatares históricos sufridos, la falta de presupuesto y las condiciones geográficas han condicionado la situación actual de la Catedral, pareciendo más desolada y menos solemne que sus hermanas.

La restauración que en estos momentos se está llevando a cabo, sobre todo lo que atañe a la iluminación, va a transformar la concepción que sobre las plantas de salón existe. En concreto la magnificencia que esta Catedral muestra después de su rehabilitación hacen pensar que este proyecto fue un logro arquitectónico dentro del momento artístico que se vivía.

La iluminación permite observar como esos pilares que sustentan el presbiterio y sirven de bisagra entre éste y el crucero, ascienden y dotan de verticalidad el eje que enmarca el centro de atención de los fieles. Esto es un elemento gótico en su esencia.

En relación con la trayectoria seguida por Egas, cabe decir que se encontraba en un momento de compromiso entre la tradición gótica y las posibilidades, mucho más libres, que le proporcionaba la planta de salón. Éstas tuvieron poco éxito por el deseo emulador de la corriente renacentista, considerando las tendencias que vienen de fuera como algo más novedoso y avanzado. Los arquitectos españoles deben seguir los libros de Alberti, Ghiberti, Sagredo ${ }^{17}$, etc. y trabajar a lo romano.

Esta planta de salón se vio afectada por el coro, heredado y ubicado en ese lugar en tiempos anteriores. De hecho la documentación permite seguir como en algunas ocasiones, en estos años estudiados, el Cabildo se reúne normalmente en la capilla de San Pedro mártir que está en el cláustro, en alguna ocasión en el coro y una vez detrás de él junto a la puerta que da al palacio de los duques.

17 Diego de Sagredo, Medidas del Romano (1526). Edición F. Marias y A. Bustamante. Madrid. Dirección General de Bellas Artes. Colegio de Aparejadores. 1986. 
En la transformación de finales del siglo $x v$ El claustro y el coro se respetan.

Enrique Egas llegó a la ciudad de Granada en diciembre de $1521^{18}$, procedente de la de Toledo y contó con la capacitada ayuda de Sebastián de Alcántara que recibió su primera paga el 20 de diciembre de ese año ${ }^{19}$. ¿Conoció a este oficial en Coria?, desde luego su apellido nos muestra su procedencia: Alcántara.

Otra actuación importante es la reparación del órgano de la iglesia. El 14 de enero de 1482 se ven obligados a reparar los fuelles ${ }^{20}$ y en el Cabildo de 30 de mayo de 1494 se recoge: "luego el dicho señor arcediano dio su boto e dixo que por quanto a su ruego avian venydo aquí a esta çibdad dos de Toledo, Cortexo, maestro de órganos y es el mas singular onbre que ay en Castilla en su ofiçio para myrarse los órganos de esta Santa Iglesia, sy tenya algund defeto para que sea dereçase e el las avia visto y animado e avia dicho que haran de los buenos que avia en Castilla ma que estavan aviados, que sy non se aderezamos de aquí al día de navidad primero que viene que se podería a ello» ${ }^{21}$. El texto continúa con la votación favorable para que se arreglen y "que el dicho Cortexo los quería amañar $e$ non queria dinero fasta que los aderezase e asentase a vista de maestros e que esto pedia para estio" 22.

También se constatan aprovisionamientos de madera que ponen en evidencia que se está trabajando en la modificación del templo. En el Cabildo de 12 de mayo de 1495 descubrimos: «iten mandaron al dicho Cabeçalino que de la dicha iglesia de a Estevan González, carpintero, los mile e trescientos e çinco maravedis que le mandaran dar por rason de çierta madera, e cartas ${ }^{23}$.

Los trabajos de los canteros se reflejan en las Actas Capitulares de forma lacónica pero constante, 13 de enero de $1497^{24}, 3$ de febrero de $1497^{25}$, el ocho de junio de este año aparece «Juan García, cantero», al que tienen que pagarle «quinze mile maravedís para con en pague a los carreteros que trahen piedra para las obras de la iglesia» ${ }^{26} \mathrm{y}$ al final del

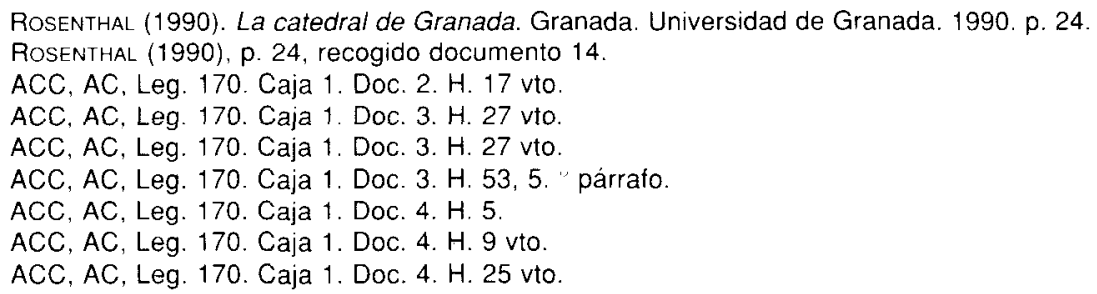


mes, el veintiséis de junio tienen que darle a este cantero, de sus tercios, treinta mil maravedís "que he de aver el dicho su tyo por rason de las capillas" ${ }^{27}$. Etc.

El 3 de febrero de 1497 «recibieron por ofiçial para haser la çerca de la dicha iglesia a Tordesillas, e se asentaron veynte reales de salario para quel mayordomo de la iglesia gelos pague cada un año de las rentas de la fabrica, e cartas. E que gose de las libertades que los otros ofiçiales gozan» ${ }^{28}$.

El 29 de abril de 1497 «iten mandaron al contador que de los maravedís de la iglesia, de a Rodrigo de Vidana quinze reales pa en cuenta de los çinquenta reales que le dan por el trabajo que pasa en la obra de las capillas e dando gelos. Carta" ${ }^{29}$. Más adelante vuelven a demandar todo el dinero que el Cabildo pudiera obtener, para abonárselo "al maestro de las capillas e a Juan García su sobrino e provisor» "30.

Sobre la adquisición de sedas y brocados para ornamentos y capas ${ }^{31}$ encontramos muchas alusiones ${ }^{32}$. Normalmente acuden a Medina del Campo ${ }^{33}$. Posteriormente los materiales que se obtenían les eran encomendados al sastre Francisco Arias ${ }^{34}$, para que confeccionara las prendas. El 27 de abril de 1495 los señores del Cabildo mandan a Alonso de Jahen que pague a este sastre «...dos mile maravedis que le mandaron dar por los caminos que echó a Medina a comprar los brocados e sedas para las capas ... los dichos señores lo reciben e reçibieron por ofiçial de la fabrica e cartas... e mas le mandaron dar quinientos reales del trabajo que tuvo que faser las dichas capas" ${ }^{35}$.

En algunos escritos sobre la Catedral de Coria se hace alusión a la falta de numerario para acometer las obras de la Iglesia.

Por lo que hemos podido leer en sus documentos la Catedral de Coria se sustentaba de lo que aportaban los propios canónigos, el obispo y otros

\footnotetext{
${ }^{27} \mathrm{ACC}, \mathrm{AC}$, Leg. 170. Caja 1. Doc. 4. H. 26, esta deteriorada la esquina del documento, pero to que hemos dicho se ve bien.

28 ACC, AC, Leg. 170. Caja 1. Doc. 4. H. 9vto.

29 ACC, AC, Leg. 170. Caja 1. Doc. 4. H. 20 vto.

30 ACC, AC, Leg. 170. Caja 1. Doc. 4. H. 20 vto. 5 de mayo de 1497.

31 ACC, AC, Leg. 170. Caja 1. Doc. 3. H. 41, también adquieren "13/otras cosas de seda" y "12/ornamentos" (17-2-1495).

32 ACC, AC, Leg. 170. Caja 1. Doc. 3. H. 2 vto. (10-10-1494), ACC, AC, Leg. 170. Caja 1. Doc. 3. H. 26 (23-5-1494), ACC, AC, Leg. 170. Caja 1. Doc. 3. H. 44 (3-4-1495).

33 ACC, AC, Leg. 170. Caja 1. Doc. 3. H. 26. ACC, AC, Leg. 170. Caja 1. Doc. 3. H. 41.

34 ACC, AC, Leg. 170. Caja 1. DoC. 3. H. 44 (3-4-1495).

35 ACC, AC, Leg. 170. Caja 1. Doc. 3. H. 46 vto.
} 
cargos. De tal forma que el obispo Pedro Ximénez de Préxamo fue alabado por los beneficios que otorgó a su iglesia. En otros casos los canónigos compran casas, arriendan posesiones del cabildo y son la fuente de ingresos de la mesa capitular y fábrica. También es habitual que las rentas de la iglesia estén controladas por cargos eclesiásticos, siendo ellos los encargados de arrendar las rentas.

Cuando a partir de $1495^{36}$ se decide que las rentas deben ser satisfechas en subasta pública, vemos que el acto oficial se realiza pero los que pujan y se hacen cargo de los arrendamientos son miembros del propio cabildo.

Ésto en la Catedral de León no sucede. Hasta 1492 está en manos de los judíos o en comandas en las que en ocasiones interviene algún capitular y señores poderosos de la ciudad y territorio de este obispado. Después de esta fecha desaparecen los nombres judíos pero no es corriente que se hagan cargo los capitulares.

El 2 de junio de 1497 los capitulares se ven obligados a vender la aceña de la conejera a Alonso de Jahen, uno de los canónigos y mayordomo de la iglesia, que fue el que más dinero entregó al Cabildo. Entre otras cosas resaltamos «luego los dichos señores dean e cabilldo dixeron que por quanto ellos $\operatorname{los}^{37}$ "dias pasados acatando e aviendo respeto a las obras e edefiçios que se hazen de nuevo en la dicha yglesia de que tienen a su neçesidad .... e para acabar e poner en perfección e efeto la dicha iglesia tiene poca renta ... tiene mucha neçesidad que se acaben del todo por el daño que pueda venir a redundar a la dicha iglesia e tesoros della por estar abierta e derocada mucha parte della e los ofiçios divignos non se disen tan enteramente .... dava por ellas çinquenta e çinco mile maravedís que de la puja postrimera e de mayor preçio e cantidad por que non se ha podido hallar que en tanto en más diese.... " ${ }^{38}$.

En este período observamos que en la Catedral de Coria se producen usurpación de bienes de la mesa y de la fábrica capitular por parte de las monjas, la Orden militar de Alcántara, miembros cabildo, incluido el obispo, los Reyes...etc. En una de las disputas que el cabildo tiene con el obispo ${ }^{39}$

36 En la Catedral de León estos actos venían siendo públicos y con notarios desde el comienzo de las actas que se conservan. Aqui no se dice hasta el 25 de julio de 1495 «se subasten y se den recaudadores en público", y se subaste con notarios. ACC, AC, Leg. 170. Caja 1. Doc. 3. H. 55.

ACC, AC, Leg. 170. Caja 1. Doc. 4. H. 23.

ACC, AC, Leg. 170. Caja 1. Doc. 4. H. 23 vto

39 ACC, AC, Leg. 170. Caja 1. Doc. 3. H. 33 vto. Le visitan por que el litigio se centraba en los diezmos que pertenecian a su encomienda (21 de noviembre de 1494). 
acuden ante el Comendador de Acehuche. Esto obliga a iniciar numerosos pleitos, pagando importantes sumas al fiscal y a los diversos notarios.

Estos hechos merman el dinero destinado a la fábrica de la iglesia: el día 7 de mayo de 1494 "yten mandaron a los canonigos Romero absente e Mingalos presente e Montes raçionero absente que den diez mile maravedis a Gonzalo Ximenes Peres fiscal de los de la fabrica e mandaron al vicario Alonso Peres raçionero su reçebtor que de los dichos diez mile maravedis de las prebendas de todo el cabilldo en Medina, para pagar los dichos diez mile maravedis que se toman de la fabrica" ${ }^{40}$.

Otro dato de interés lo encontramos el 19 de junio de 1495, en el que se habla de la barca nueva que se hace por el regimiento de la ciudad y a la que contribuyen con sus bienes el Cabildo. La iglesia Catedral mandó «al licençiado Pedro Gonzalez del Castillo, canónigo, su destrebuydor que de las rentas de la dicha destrebuyçion de mill maravedis al regimiento de esta dicha çibdad e aquien portillos lo ovieren de aver, para ayudar a la barca nueva que agora fisieron para audar en este río e cartas» ${ }^{41}$.

También encontramos el 6 de noviembre de 1495 que el Cabildo manda a "Cabeçalino que de los maravedís de la iglesia de a Juan Días quinientos maravedís para comprar pergamino para el salterio que fase para la dicha iglesia" ${ }^{42}$.

El 5 de junio de 1497 los señores del Cabildo «mandan a Cabeçalino y a Mingalos, presentes y a Mata, ausente, que saquen del arca -ellos tienen la llave - la mitra y el báculo del señor obispo don Pedro Ximénez de Préxamo para llevarlo a Salamanca y que lo tasen porque el obispo de Plasencia don Gutierre, está interesado en adquirirlo. Es cierto que la iglesia Catedral de Coria necesita de dinero líquido para llevar a cabo sus reformas.

Resulta curioso el contrato y escrituras que el Cabildo realiza con Alonso de Jahén, cuando le vende la aceña de la conejera, ya que recoge todos los términos y actos señoriales que todavia están vigentes y que no hemos querido copiar aquí por tratarse éste de un estudio artístico.

\footnotetext{
ACC, AC Leg. 170. Caja 1. Doc. 3. H. 23.

ACC, AC, Leg. 170. Caja 1. Doc. 3. H. 53 vto.

ACC, AC, Leg. 170. Caja 1. Doc. 3. H. 63 vto.
} 